\title{
From Simplicity to Complexity via Subcomponent Self-Assembly
}

\author{
Marie Hutin, David Schultz, and Jonathan R. Nitschke $\S^{\text {* }}$ \\ §Werner Prize Winner 2007
}

\begin{abstract}
Subcomponent self-assembly allows the construction of complex architectures from simple building blocks via the formation of covalent bonds around metal templates. Since both covalent and coordinative bonds are formed reversibly, a wealth of rearrangement reactions are possible involving substitution at both intraligand and metal-ligand bonds. If the possibilities latent within a set of subcomponents and metal ions are understood, one may also select specific structures from among dynamic libraries of products. The parallel preparation of structures from mixtures of subcomponents is also possible, as is the direction of subcomponents to specific sites within product structures.
\end{abstract}

Keywords: Subcomponent self-assembly

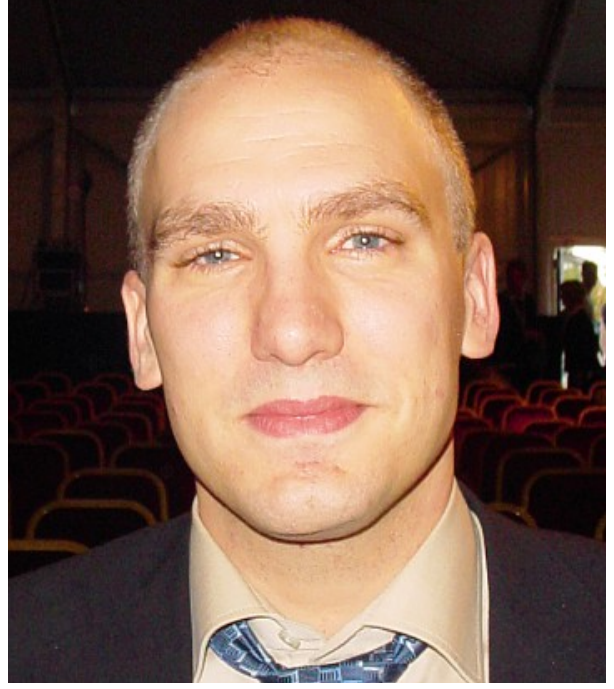

Jonathan Nitschke was born in 1973 in Syracuse, New York, USA. He received his Bachelor's degree in chemistry from Williams College in 1995, and his PhD from the University of California, Berkeley in 2001 under the supervision of T.

*Correspondence: Dr. J. R. Nitschke The University Chemical Laboratory University of Cambridge Lensfield road

Cambridge, CB2 1EW

UK

Tel.: + 441223336324

Fax: + 441223336362

E-mail: jrn34@cam.ac.uk
Don Tilley. He then undertook postdoctoral studies with Jean-Marie Lehn in Strasbourg under the auspices of a US NSF fellowship, and in 2003 he started his independent career as a maître-assistant (fixed-term lecturer) in the Organic Chemistry Department of the University of Geneva. He was the first recipient of the European Young Chemist Award in August 2006 and became a Swiss National Science Foundation Assistant Professor in August 2007. Since November 2007 he has held the position of University Lecturer and Walters-Kundert Next Generation Fellow at the University of Cambridge.

\section{Introduction}

Human intelligence has proven skilled at examining spontaneously organized structures and deducing the principles of selforganization that lead to their formation from less complex matter. This kind of deductive reasoning is one of the cornerstones of science, allowing for future predictions to be made based upon the principles uncovered.

Through understanding chemical selforganization, new synthetic possibilities arise in ways that are not possible in the other sciences, for the idea of synthesis is more integral to chemistry than to biology or physics. When chemical bonds are formed in well-defined ways under thermodynamic,,$^{[1]}$ as opposed to kinetic, ${ }^{[2]}$ control, one may refer to the resulting self-organization process as 'self-assembly'. An under- standing of the rules and principles guiding a self-assembly process can allow one to utilize these rules synthetically, creating new structures possessing new functions.

As one example, the observation of hydrogen bonding ${ }^{[3]}$ in natural systems such as peptide helices and DNA base pairs led to a theoretical understanding of this phenomenon. This understanding has permitted the use of hydrogen bonding in synthesis, leading to the preparation of such diverse structures as Rebek's capsules, ${ }^{[4]}$ Lehn's supramolecular polymers ${ }^{[5]}$ and Whitesides' rosettes. ${ }^{[6]}$

Over the course of the past four years, we have developed and employed the technique of subcomponent self-assembly toward the creation of increasingly complex structures. This technique, itself a subset of metallo-organic self-assembly, ${ }^{[7]}$ involves the simultaneous formation of covalent (carbon-heteroatom) and dative (heteroatom-metal) bonds, bringing both ligand and complex into being at the same time. The roots of subcomponent self-assembly lie in the template synthesis of Busch. ${ }^{[8]}$ Before and after the inception of our research program, other researchers have employed this method to synthesize a wealth of structures, including macrocycles, ${ }^{[9]}$ helicates ${ }^{[10,11]}$ rotaxanes, ${ }^{[12]}$ catenanes, ${ }^{[13]}$ grids, ${ }^{[14,15]}$ and Borromean ${ }^{[16]}$ as well as Solomon ${ }^{[17]}$ links.

Our research program has been developed along four main lines. First, construction: we have investigated the parameters that can be used to induce selectivity in self-assembly, and its possibilities and lim- 
its. Second, we investigated the thermodynamic parameters allowing these structures to rearrange and reorganize in well-defined ways. Third, we have studied the parameters allowing complex dynamic combinatorial libraries to be sorted by taking advantage of the thermodynamic preferences of the basic building blocks employed, the metal ions and ligand subcomponents. Fourth, related to the idea of sorting, we have investigated the possibilities of the transfer of chiral information within the structures that we have synthesized.

\section{Construction}

\subsection{Aqueous Copper(I)-templated Subcomponent Self-assembly}

The first study we undertook ${ }^{[18]}$ validated the use of subcomponent self-assembly using aqueous copper(I), as well as taking initial steps in the directions of construction, substitution, and sorting.

In aqueous solution $\mathrm{Cu}^{\mathrm{I}}$ is frequently observed to disproportionate to $\mathrm{Cu}^{\mathrm{II}}$ and copper metal, and imines are in most cases the minority species when amines and carbonyl compounds are mixed in water. ${ }^{[19]}$ When imines and copper(I) are present in the same solution, however, this pattern of stability reverses. Imines are excellent ligands for $\mathrm{Cu}^{\mathrm{I}}$, stabilizing the metal in this oxidation state, and metal coordination can prevent imines from hydrolyzing. We were thus able to prepare complex $\mathbf{1}$ from the precursors shown at the left in Scheme 1. [18]

Although thermodynamically stable in aqueous solution, complex 1 nonetheless readily underwent covalent imine substitution in the presence of sulfanilic acid to form 2 (Scheme 2).

This reaction occurred with greater than 95\% selectivity. The driving force behind this imine exchange may be understood in terms of the difference in acidity between sulfanilic acid $\left(p K_{\mathrm{A}}=3.2\right)$ and taurine $\left(p K_{\mathrm{A}}\right.$ =9.1), which favors the displacement of the protonated form of the weaker acid (taurine)

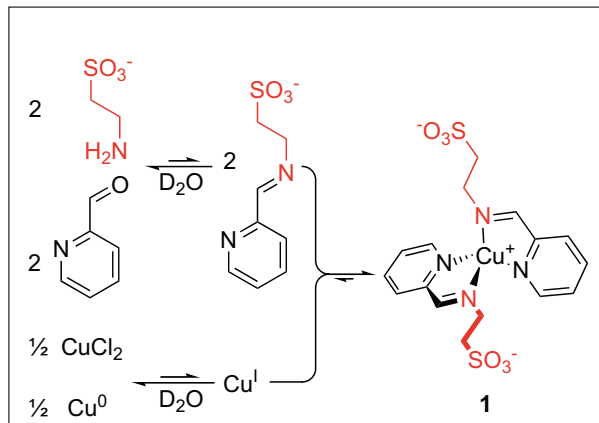

Scheme 1. Mutual stabilization of imines and $\mathrm{Cu}^{\mathrm{l}}$ in aqueous solution

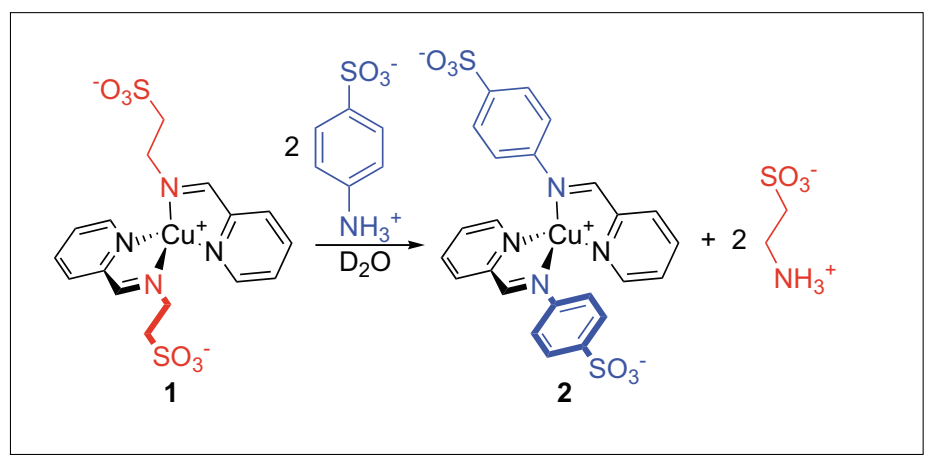

Scheme 2. Subcomponent substitution driven by differences in acidity

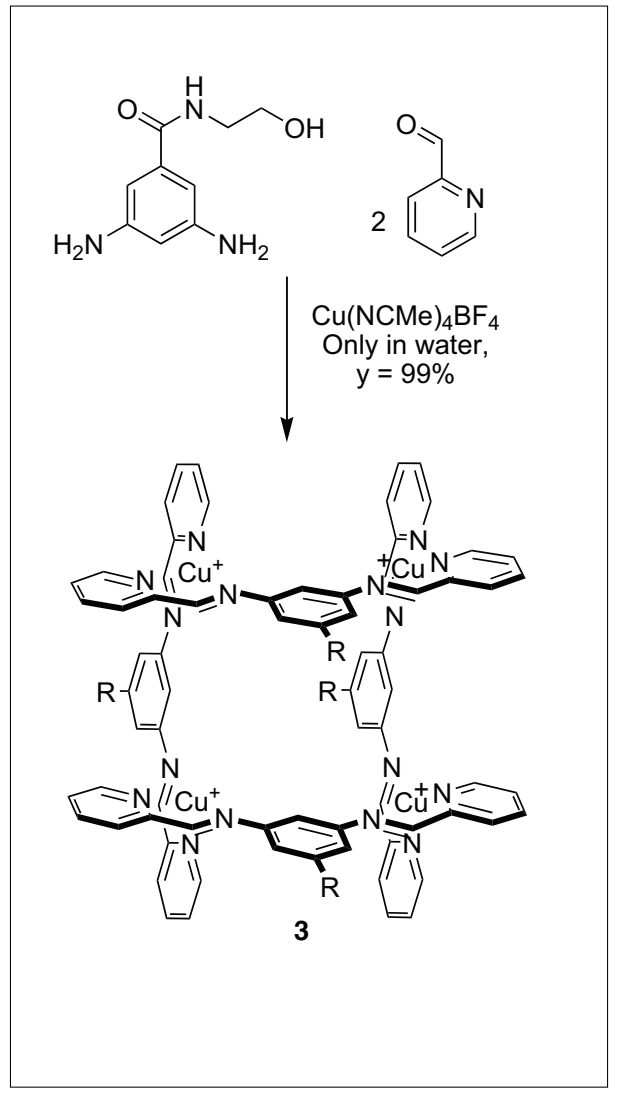

Scheme 3. Self-assembly of a $[2 \times 2]$ grid complex; ${ }^{[15]} \mathrm{R}=-\mathrm{CONHCH}_{2} \mathrm{CH}_{2} \mathrm{OH}$ from 1 and the incorporation of the deprotonated form of the stronger acid (sulfanilic acid) during the formation of 2. ${ }^{[18]}$

The bis(iminopyridine) copper(I) motif of 1 served as a versatile tecton in the construction of other, more complex structures, as described below.

\subsection{Tetracopper(I) $\operatorname{grid}^{[15]}$}

The mixture of 3,5-diamino-N-(2-hydroxy-ethyl)-benzamide with pyridinecarboxaldehyde in deuterium oxide solution under an argon atmosphere gave a complex dynamic combinatorial library of ligands, as observed by NMR spectroscopy. Upon addition of copper(I) to this mixture, only one ligand was selected, thus forming quantitatively tetra-copper(I) grid 3 (Scheme 3 ). This grid can be formed uniquely in water, and even if it is pre-synthesized it undergoes decomposition in those other solvents in which it is soluble. The crystal structure of $\mathbf{3}$ shows a distorted coordination environment around copper(I). We attributed the stability of this complex to the hydrophobic effect.[15]

\subsection{Double helicates ${ }^{[11,20]}$}

The reaction of sulfanilic acid, copper(I) oxide, 2,9-diformyl-1,10-phenanthroline in water led to the quantitative formation of dicopper double helicate 4 . A series of simi-

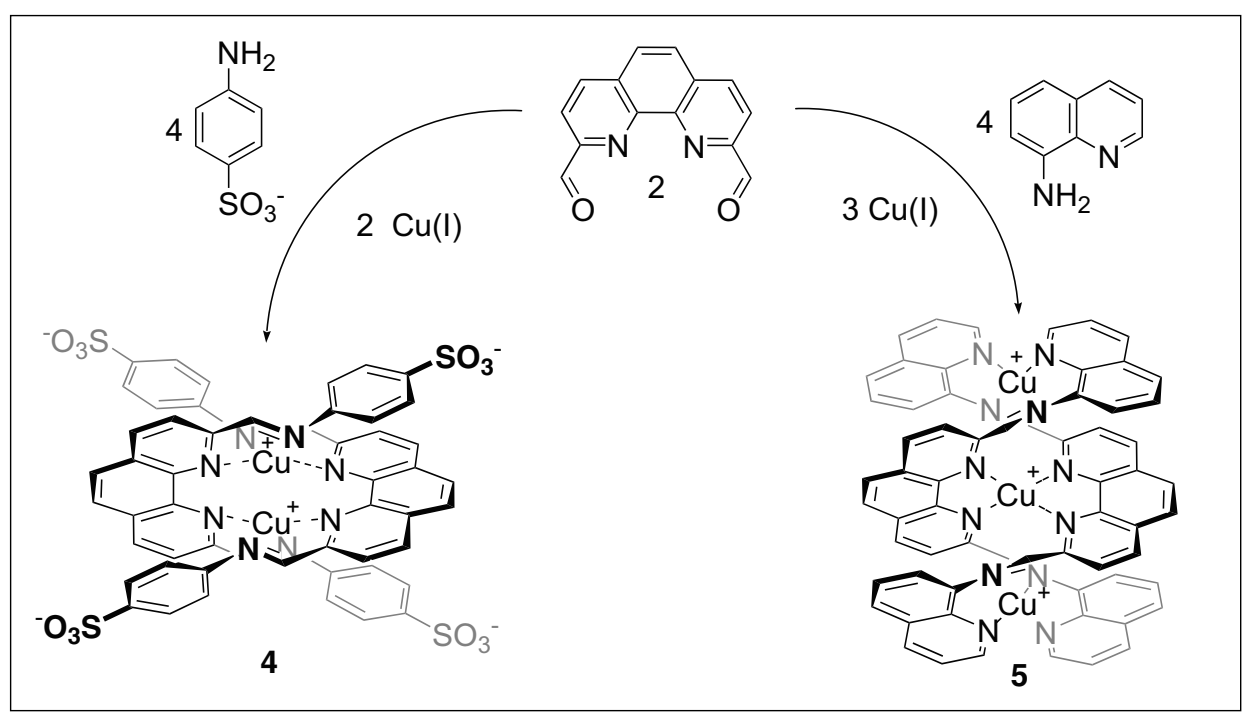

Scheme 4. Syntheses of dicopper helicate $\mathbf{4}$ and tricopper helicate 5 


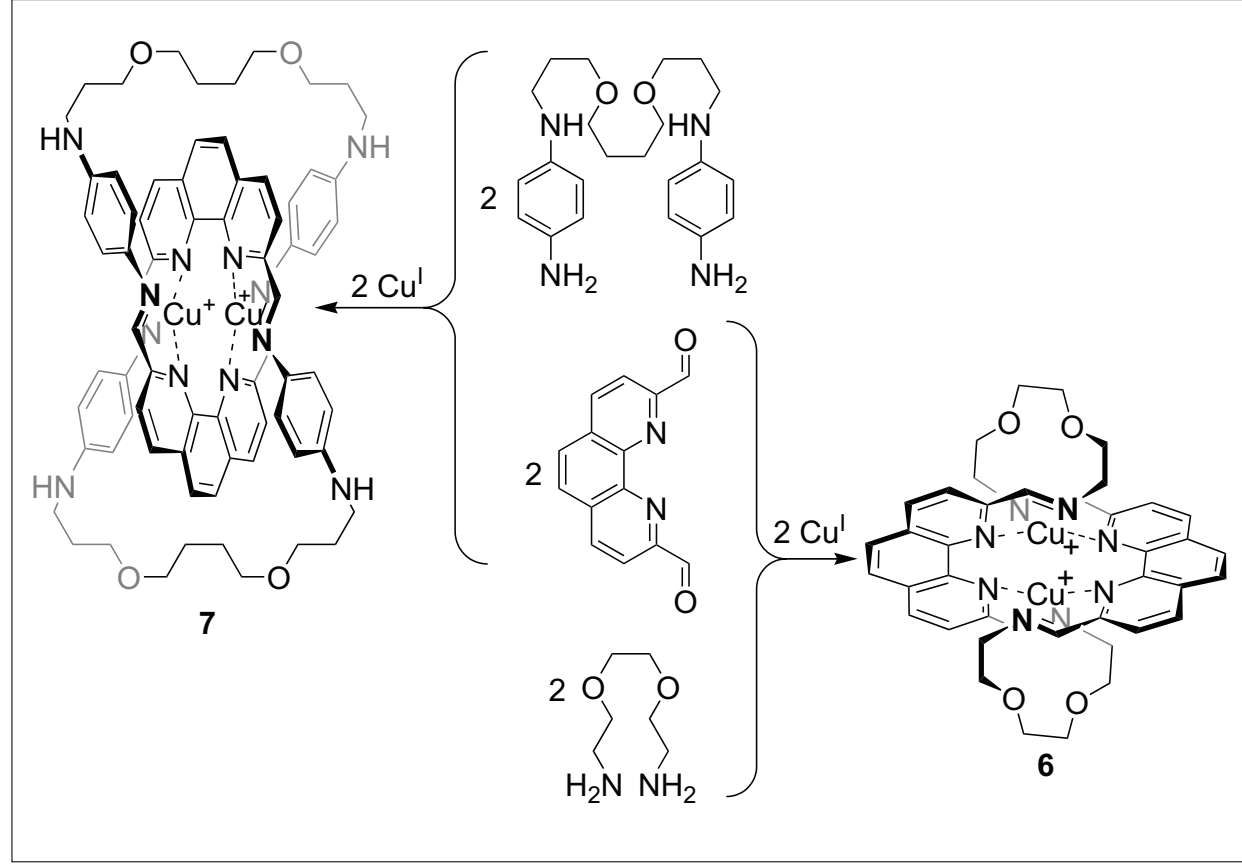

Scheme 5. Syntheses of macrocycle 6 and catenate 7

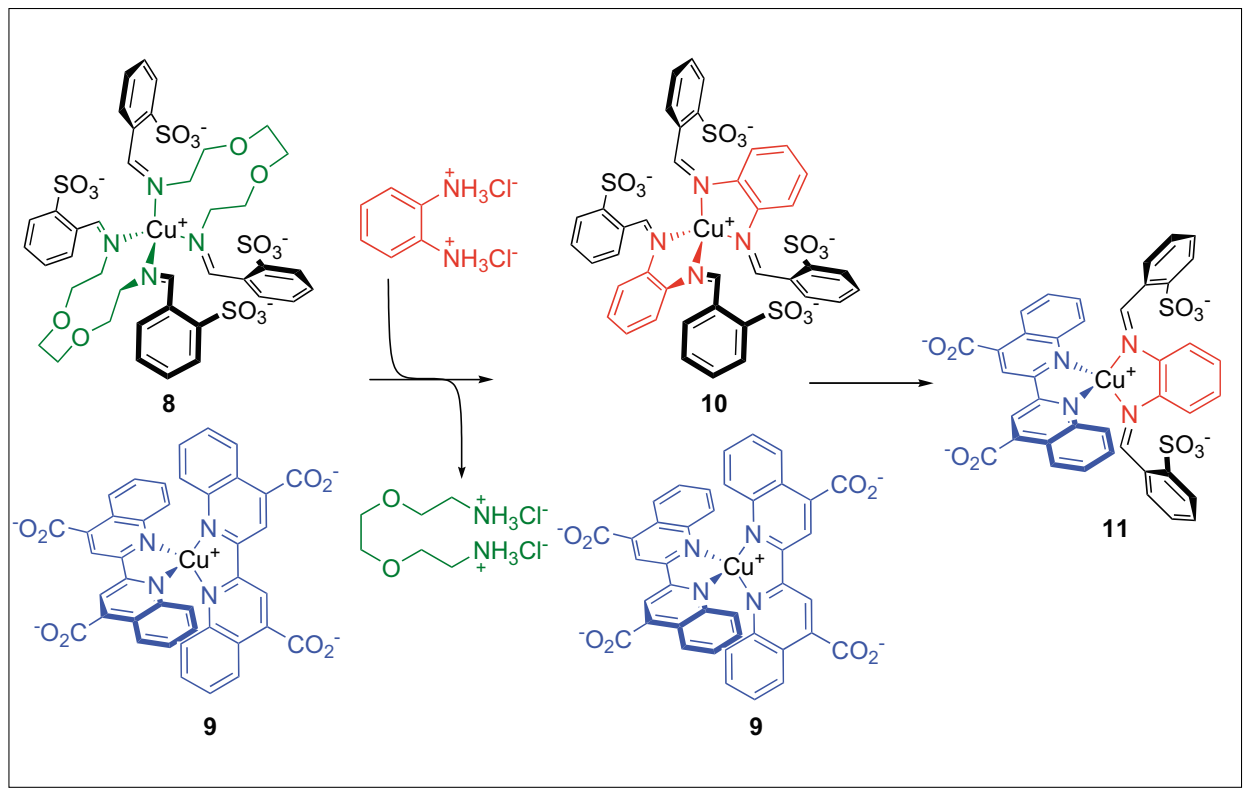

Scheme 6 . The cascade reaction between $\mathbf{8}, \mathbf{9}$, and o-phenylenediamine dihydrochloride, yielding 11

lar complexes has been synthesized using other amine subcomponents.

A tricopper double helicate could also be synthesized by a modified preparation of the dicopper helicate. When three equivalents of copper(I) was used with 8-aminoquinoline as the amine, tricopper helicate $\mathbf{5}$ was the unique observed product (Scheme 4).

\subsection{Catenates and Macrocycles[21]}

The reaction of the short diamine 2-[2-(2-amino-ethoxy)-ethoxy]-ethylamine with 1,10-phenanthroline-2,9-dialdehyde and copper(I) tetrakis(acetonitrile) tetrafluoroborate in aqueous solution gave
NMR spectroscopy (Scheme 5). Its catenated topology was confirmed by the group of Christoph Schalley using fragmentation analysis via MS-MS spectrometry.[21]

Through the appropriate choice of the ligand, its length and its rigidity, it is thus possible to program the topology of the structure. Catenate $\mathbf{7}$ is helically chiral in addition to possessing the possibility of becoming topologically chiral through the incorporation of an asymmetric dianiline. This is currently under investigation.

\section{Rearrangement}

\subsection{Cascade Rearrangement}

Bis(diimine) complexes such as $\mathbf{8}$ (Scheme 6) were observed to possess a rich substitution chemistry. ${ }^{[22]}$ Complex 8 reacted cleanly with $o$-phenylenediamine dihydrochloride in aqueous solution to give $\mathbf{1 0}$ as shown in Scheme 6. As in the case of the system of Scheme 2, such $p K_{A}$-driven transimination reaction favors the displacement of the protonated form of the weaker acid (aliphatic diammonium) and the incorporation of the deprotonated form of the stronger acid (aromatic diammonium). ${ }^{[11,18]}$ In the presence of copper(I) bis(biquinoline) complex 9, the newly-formed complex $\mathbf{1 0}$ readily underwent ligand exchange ${ }^{[23]}$ to give a mixed-ligand species as the thermodynamic product. Starting complex 8 was observed to be unreactive towards ligand exchange with complex $\mathbf{9}$, possibly as a result of the different steric properties of the two complexes. This observation opened the door to a new kind of cascade reaction operating at both covalent and coordinative levels. Once the imine (covalent) exchange had occurred, ligand (coordinative) exchange between the copper complexes $\mathbf{9}$ and $\mathbf{1 0}$ could then happen, affording the mixed-ligand complex $\mathbf{1 1}$ as the unique product.

\subsection{Electronic Effects}

We have shown that the electronic effect of the substituent in para-substituted aniline, as measured by the Hammett $\sigma_{\text {para }}$ parameter, ${ }^{[24]}$ may be used as a driving force in the reaction of subcomponent substitution within copper(I) complexes. ${ }^{[25]}$ The quantification of these electronic effects using the Hammett equation allowed us to predict product identities and yields with good accuracy. These results were used to design a three-step transformation of a series of copper(I) containing structures (Scheme 7). Each step proceeded in predictably high yield, as calculated from $\sigma$ differentials, using the Hammett equation. The interest of this experiment is that we can change the topology of the complex at each step. Starting from 12, the first transformation 


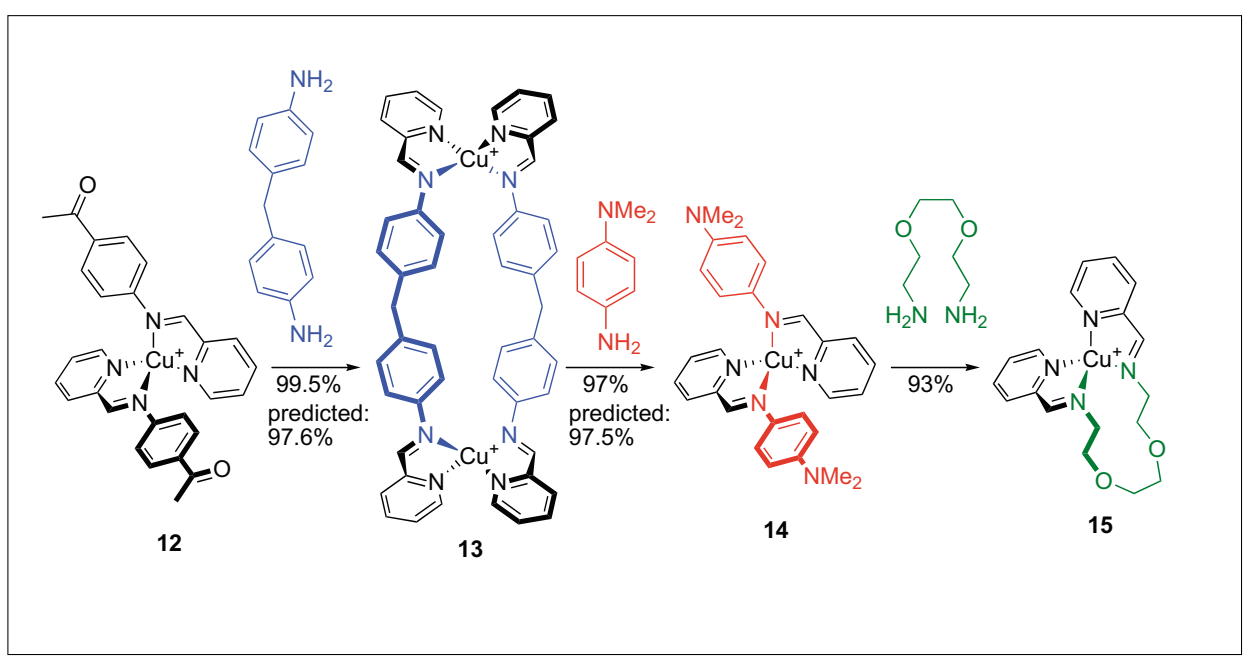

Scheme 7. A one-pot series of transformations, mixing substituent electronic effects and the chelate effect to provide driving forces for imine exchange

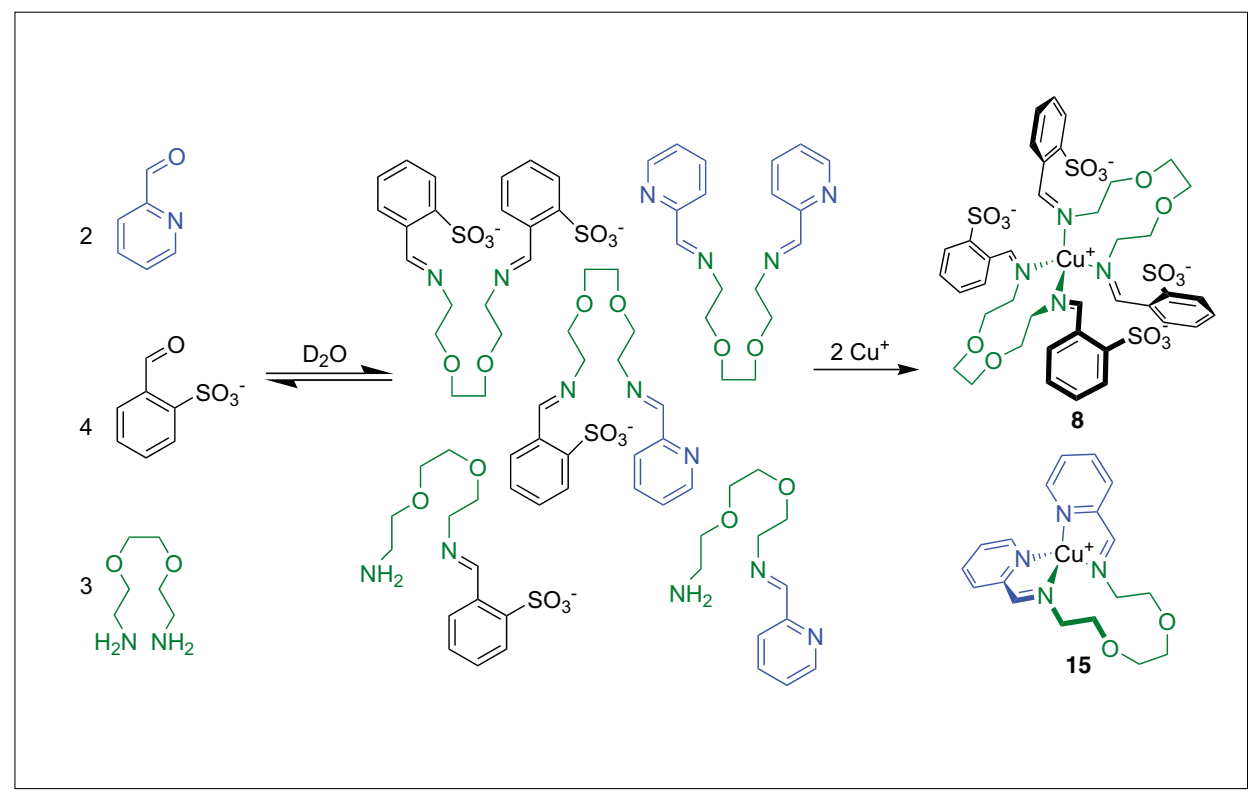

Scheme 8 . The simultaneous formation of $\mathbf{8}$ and $\mathbf{1 5}$ from a dynamic library of ligands and ligand components

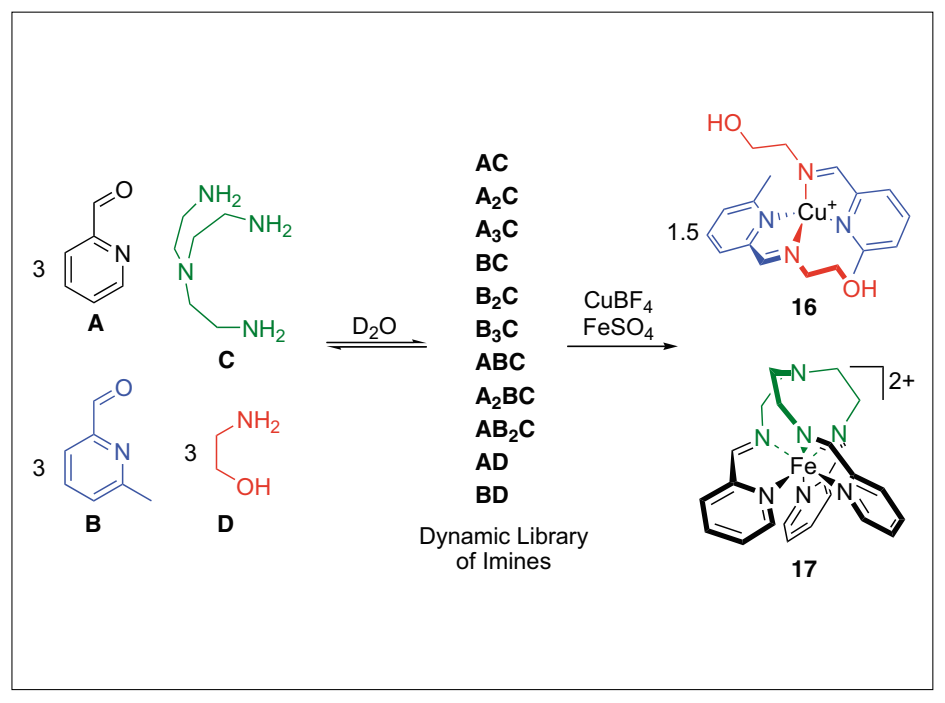

Scheme 9. The formation of a dynamic combinatorial library of ligands, and the collapse of this library following the addition of $\mathrm{Cu}^{l}$ and $\mathrm{Fe}^{\text {ll }}$ gives the dicopper macrocycle 13. ${ }^{[26]}$ Then the mononuclear topology can be readily recovered after addition of an electron-rich aniline giving 14. Finally, addition of an aliphatic diamine leads to the mononuclear macrocycle 15. This final substitution is driven by the entropy gain associated with the formation of a more chelating ligand.

\section{Sorting}

Since the reversible character of the processes involved in subcomponent selfassembly allows for dynamic rearrangement at both covalent and coordinative level, it is possible to envisage systems where mixtures of subcomponents, which react together to generate dynamic libraries ${ }^{[27]}$ of ligands, could be sorted into a limited number of structures using the selectivities imposed by metal ions. The metal ions would select the ligands best able to form stable complexes. It is thus worthwhile to investigate ways in which individual subcomponents might be directed to specific locations within assemblies.

\subsection{Sorting with Copper(I)}

The mixture of 2,2'-(ethylenedioxy) bis(ethylamine) (3 equiv.) with pyridine2 -carboxaldehyde ( 2 equiv.) and benzaldehyde-2-sulfonate (4 equiv.) in water gave a mixture of products. The NMR spectra of this mixture were attributed to bis(pyridyl) imine, bis(benzaldehydesulfonate)imine, and the mixed (pyridyl)(benzaldehydesulfonate)diimine, in addition to mono-imines and unreacted amine and aldehyde starting materials (Scheme 8). The addition of copper(I) to this mixture caused an initial increase in the number of species observed, as the copper formed complexes in different ways with the various ligands present. But over several hours, equilibration processes led to the exclusive formation of complexes $\mathbf{8}$ and 15, eliminating the mixed ligand and the free ligand subcomponents from the equilibrium. ${ }^{[22]}$

Other complexes than $\mathbf{8}$ and $\mathbf{1 5}$ would be coordinatively unsaturated either at the ligands or at the metals ${ }^{[28]}$ and their formation would be entropically-disfavored. Therefore, under equilibrium conditions, such complexes were transformed into complexes 8 and 15, the only ones that are both coordinatively saturated and mononuclear.

\subsection{Choices of Iron(II) and Copper(I)}

Extending this sorting methodology further, we examined a larger self-organizing system in which $\mathrm{Fe}^{\mathrm{II}}$ and $\mathrm{Cu}^{\mathrm{I}}$ cooperate to sort a more complex dynamic library of ligands and ligand subcomponents. ${ }^{[29]}$ The aqueous mixture of pyridine-2-carboxaldehyde (3 equiv.), 6-methylpyridine-2-carboxalde- 


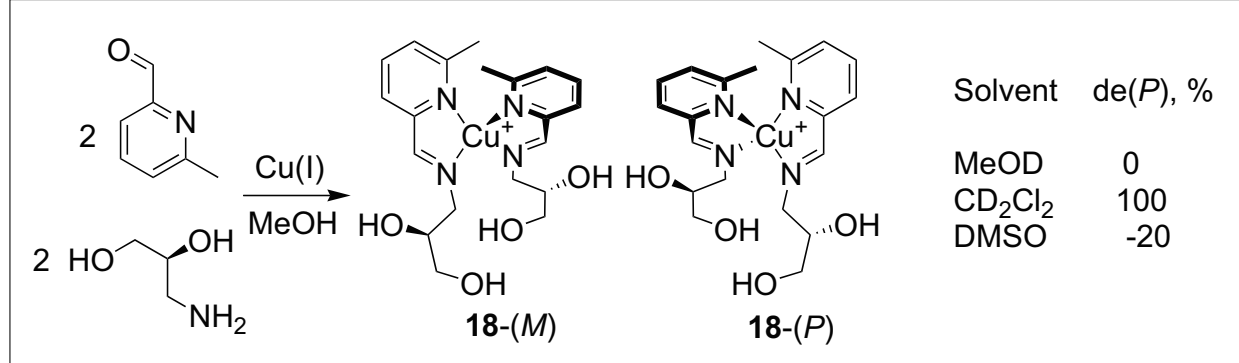

Scheme 10. Synthesis of the diastereomers of complex 18

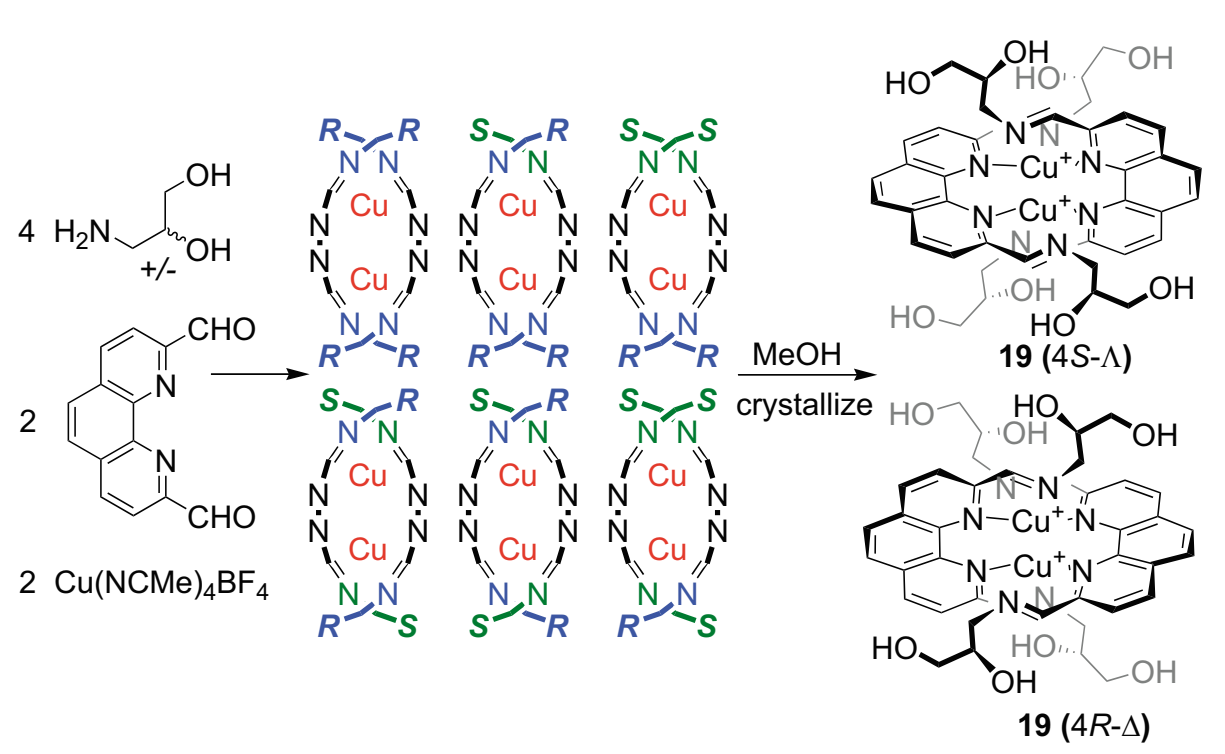

Scheme 11. Synthesis of a mixture of diastereomeric pairs of enantiomers of dicopper helicate 19 and its chiral resolution by crystallization

hyde ( 3 equiv.), ethanolamine ( 3 equiv.) and tris(2-aminoethyl)amine (1 equiv.) resulted in the formation of a dynamic library of imines, in equilibrium with the starting materials as shown in Scheme 9. The addition of copper(I) tetrafluoroborate (1.5 equiv.) and iron(II) sulfate (1 equiv.) led to the selective formation of complexes $\mathbf{1 6}$ and $\mathbf{1 7}$.

After further examination of this system, it was found that selection preferences expressed by the two metals acted in concert to deconvolute the initial library of ligands. Although these preferences do not lead to quantitative selection in the absence of one of the metals, they reinforce each other in the full mixture to select the observed products $\mathbf{1 6}$ and $\mathbf{1 7}$ from among all possible products.

\section{Chiral Induction}

\subsection{Chirality Transfer from Carbon to Copper(I) $)^{[30]}$}

The reaction of copper(I) with $S$-3-amino-1,2-propanediol and 6-methylpyridine2-carboxaldehyde in anaerobic methanol provides a one-pot template synthesis of complex 18, incorporating a new chiral ligand, in quantitative yield (Scheme 10). form. Monocrystal and powder diffraction data showed the formation of only the two enantiomers $4 S-\Lambda$ and $4 R-\Delta$ of helicate 19 , thus providing a novel example of chiral resolution during crystallization. ${ }^{[32]}$

\section{Conclusions}

The creation of structural complexity, including topological complexity, ${ }^{[13,16,17]}$ is feasible using subcomponent self-assembly, and the structures thus made may be induced to reassemble in well-defined ways using a variety of driving forces. The demonstration of directing sets of subcomponent building blocks to come together in well-defined ways also opens up the possibility of linking such subunits together covalently, such that their self-assembly instructions serve as 'subroutines' to guide the generation of a more complex superstructure.

We are currently investigating the use of subcomponent self-assembly to prepare new metal-containing polymeric materials. Following the same methodology that allowed the preparation of macrocycle $\mathbf{6}$ and catenane 7 (Scheme 5), further variations in the length, rigidity, and geometry of diamine subcomponents might allow for the generation of double-helical polymers, cyclic catenanes, or perhaps even polymeric catenanes.

Received: January 22, 2008

Proton NMR spectra in that solvent gave two sets of signals with the same intensity, consistent with the presence of identical amounts of the two diastereomers.

Results from NMR and CD analyses suggest the presence of uniquely the $P$ diastereomer in dichloromethane- $d_{2}$, and a diastereomeric excess of $20 \%$ in favour of the $M$ diastereomer in DMSO- $d_{6}$. We attributed this phenomenon to the ability of a solvent to accept hydrogen bonds from the hydroxyl groups of the ligands.

\subsection{Chiral Resolution During Crystallization $^{[31]}$}

If phenanthroline dialdehyde, racemic amine and copper(I) are mixed together, a mixture of six diastereomeric pairs of enantiomers of helicate $\mathbf{1 9}$ is expected to form (Scheme 11). Each of the two enantiomers of the amine can be incorporated at each of the equivalent sites in the helicate, which can itself have $\Lambda$ or $\Delta$ helicity. The NMR spectra were consistent with the presence of numerous diastereomers, and could not have come from two or fewer diastereomers.

When the preparation of helicate $\mathbf{1 9}$ and its diastereomers was carried out in methanol, X-ray quality crystals were observed to
[1] J. S. Lindsey, New J. Chem. 1991, 15, 153; S. J. Rowan, S. J. Cantrill, G. R. L. Cousins, J. K. M. Sanders, J. F. Stoddart, Angew. Chem., Int. Ed. 2002, 41, 898.

[2] K. C. Nicolaou, E. J. Sorensen, 'Classics in Total Synthesis', Wiley-VCH, Weinheim, Germany, 1996.

[3] S. Thomas, Angew. Chem., Int. Ed. 2002, $41,48$.

[4] F. Hof, S. L. Craig, C. Nuckolls, J. Rebek, Angew. Chem., Int. Ed. 2002, 41, 1488.

[5] V. Berl, M. Schmutz, M. J. Krische, R. G. Khoury, J. M. Lehn, Chem. Eur. J. 2002 , $8,1227$.

[6] J.A.Zerkowski, C.T. Seto, G. M. Whitesides, J. Am. Chem. Soc. 1992, 114, 5473.

[7] J. M. Lehn, 'Supramolecular Chemistry: Concepts and Perspectives', WileyVCH, Weinheim, 1995; M. Albrecht, $J$. Inclusion Phenom. Macrocyclic Chem. 2000, 36, 127; S. R. Seidel, P. J. Stang, Acc. Chem. Res. 2002, 35, 972; W.-Y. Sun, M. Yoshizawa, T. Kusukawa, M. Fujita, Curr. Opin. Chem. Biol. 2002, 6, 757; D. L. Caulder, K. N. Raymond, Acc. Chem. Res. 1999, 32, 975; B. J. Holliday, C. A. Mirkin, Angew. Chem., Int. Ed. 2001, 40, 2022; M. W. Hosseini, Acc. Chem. Res. 2005, 38, 313 .

[8] T. J. Hubin, D. H. Busch, Coord. Chem. Rev. 2000, 200, 5 .

[9] M. J. MacLachlan, Pure Appl. Chem. 2006, 78, 873; L. L. Schafer, J. R. Nitschke, S. S. 
H. Mao, F. Q. Liu, G. Harder, M. Haufe, T. D. Tilley, Chem. Eur. J. 2002, 8, 74.

[10] H. Houjou, A. Iwasaki, T. Ogihara, M. Kanesato, S. Akabori, K. Hiratani, New J. Chem. 2003, 27, 886; L. J. Childs, N. W. Alcock, M. J. Hannon, Angew. Chem. Int. Ed. 2002, 41, 4244; J. Hamblin, L. J. Childs, N. W. Alcock, M. J. Hannon, J. Chem. Soc. Dalton 2002, 164.

[11] J.R. Nitschke, D. Schultz, G. Bernardinelli, D. Gérard, J. Am. Chem. Soc. 2004, 126, 16538 .

[12] L. Hogg, D. A. Leigh, P. J. Lusby, A. Morelli, S. Parsons, J. K. Y. Wong, Angew. Chem., Int. Ed. 2004, 43, 1218.

[13] D. A. Leigh, P. J. Lusby, S. J. Teat, A. J. Wilson, J. K. Y. Wong, Angew. Chem., Int. Ed. 2001, 40, 1538.

[14] J. R. Nitschke, J. M. Lehn, Proc. Natl. Acad. Sci. U. S. A. 2003, 100, 11970; S. Brooker, S. J. Hay, P. G. Plieger, Angew. Chem., Int. Ed. 2000, 39, 1968.

[15] J. R. Nitschke, M. Hutin, G. Bernardinelli, Angew. Chem., Int. Ed. 2004, 43, 6724.

[16] K. S. Chichak, S. J. Cantrill, A. R. Pease, S.-H. Chiu, G. W. V. Cave, J. L. Atwood, J. F. Stoddart, Science 2004, 304, 1308.

[17] C. D. Pentecost, K. S. Chichak, A. J. Peters, G. W. V. Cave, J. F. Stoddart, S. J. Cantrill, Angew. Chem., Int. Ed. 2007, 46, 218.

[18] J. R. Nitschke, Angew. Chem. Int., Ed. 2004, 43, 3073.

[19] C. Godoy-Alcantar, A. K. Yatsimirsky, J. M. Lehn, J. Phys. Org. Chem. 2005, 18, 979.

[20] M. Hutin, R. Franz, J. R. Nitschke, Chem. Eur. J. 2006, 12, 4077.
[21] M. Hutin, C. A. Schalley, G. Bernardinelli, J. R. Nitschke, Chem. Eur. J. 2006, 12, 4069.

[22] D. Schultz, J. R. Nitschke, Proc. Natl. Acad. Sci. U.S.A. 2005, 102, 11191.

[23] R. D. Braun, K. J. Wiechelman, A. A. Gallo, Anal. Chim. Acta 1989, 221, 223.

[24] L. P. Hammett, Chem. Rev. 1935, 17, 125; H. H. Jaffe, Chem. Rev. 1953, 53, 191.

[25] D. Schultz, J. R. Nitschke, J. Am. Chem. Soc. 2006, 128, 9887.

[26] M. J. Hannon, C. L. Painting, A. Jackson, J. Hamblin, W. Errington, Chem. Commun. 1997, 1807; J. Keegan, P. E. Kruger, M. Nieuwenhuyzen, N. Martin, Cryst. Growth Des. 2002, 2, 329.

[27] J. M. Lehn, Chem. Eur. J. 1999, 5, 2455; K. Severin, Chem. Eur. J. 2004, 10, 2565 I. Saur, R. Scopelliti, K. Severin, Chem. Eur. J. 2006, 12, 1058; P. T. Corbett, J. Leclaire, L. Vial, K. R. West, J. L. Wietor, J. K. M. Sanders, S. Otto, Chem. Rev. 2006, 106, 3652.

[28] M. G. B. Drew, A. Lavery, V. McKee, S. M. Nelson, J. Chem. Soc. Dalton 1985, 1771.

[29] D. Schultz, J. R. Nitschke, Angew. Chem., Int. Ed. 2006, 45, 2453

[30] M. Hutin, J. R. Nitschke, Chem. Commun. 2006, 1724.

[31] M. Hutin, C. J. Cramer, L. Gagliardi, A. R. M. Shahi, G. Bernardinelli, R. Cerny, J. R. Nitschke, J. Am. Chem. Soc. 2007, 129, 8774.

[32] L. Pasteur, Ann. Chim. Phys. 1848, 24, 442. 